\title{
Changing the site of delivery of thrombolytic treatment for acute myocardial infarction from the coronary care unit to the emergency department greatly reduces door to needle time
}

\author{
C T Hourigan, D Mountain, P E Langton, I G Jacobs, I R Rogers, G A Jelinek, \\ P L Thompson
}

\begin{abstract}
Objective-To quantify the change in door to needle time when delivery of thrombolytic treatment of acute myocardial infarction was changed from the coronary care unit to the emergency department.

Design-A comparative observational study using prospectively collected data.

Setting-Coronary care unit and emergency department of an Australian teaching hospital.

Participants-89 patients receiving thrombolysis in coronary care unit between June 1994 and January 1996, and 100 patients treated in the emergency department between April 1997 and May 1998.

Interventions-From April 1997, by agreement between cardiology and emergency medicine, all patients with acute myocardial infarction receiving thrombolysis were treated by emergency physicians in the emergency department.

Main outcome measure-Door to needle time measured from time of arrival at the hospital to start of thrombolysis. Other outcomes included pain to needle time and mortality.

Results-Median door to needle times were less for patients treated in the emergency department than in the coronary care unit ( 37 minutes, 95\% confidence interval (CI) 33 to $44 v 80$ minutes, $95 \%$ CI 70 to 89 , respectively; $\mathrm{p}<0.0001$ ). Door to needle time was under 60 minutes in $83 \%$ of emergency department patients and $26 \%$ of coronary care unit patients ( $57 \%$ difference, $95 \%$ CI $45 \%$ to $69 \% ; \mathrm{p}<0.0001)$. Median pain to needle time was less for emergency department patients than for coronary care unit patients (161 minutes, 95\% CI 142 to $177 v 195$ minutes, 95\% CI 180 to $209 ; \mathrm{p}=0.004$ ); times of less than 90 minutes occurred in $18 \%$ of emergency department patients $v 1 \%$ of coronary care unit patients ( $17 \%$ difference, $95 \%$ CI $9 \%$ to $25 \%$; $<0.05)$. Overall mortality was similar in patients treated in the emergency department and the coronary care unit. Conclusions-With a collaborative interdepartmental approach, thrombolytic treatment of acute myocardial infarction was more rapid in the emergency department, without compromising patient safety. This should improve the outcome in patients with infarcts treated with thrombolytic agents.

(Heart 2000;84:157-163)
\end{abstract}

Keywords: thrombolysis; door to needle time; treatment delay; acute myocardial infarction

Department of Emergency Medicine, Sir Charles Gairdner Hospital, Verdun Street, Nedlands, Perth 6009, Australia C T Hourigan D Mountain

I R Rogers

Department of Cardiovascular Medicine, Sir Charles Gairdner Hospital, Perth, Australia P L Thompson

Faculty of Medicine, University of Western Australia, Perth, Australia

P E Langton

I G Jacobs

G A Jelinek

Correspondence to: Dr Mountain email: David.Mountain@ health.wa.gov.au

Accepted 25 April 2000
The treatment of acute myocardial infarction has been studied intensively over the past 15 years. Proven benefits have led to the routine administration of thrombolytic agents in such patients. ${ }^{12}$ The data show that thrombolytic agents decrease overall 30 to 35 day mortality by $18-25 \%$, with increasing benefit as the time from onset of pain to thrombolysis is reduced..$^{1-4}$

One way of reducing this time is by minimising the delay in starting thrombolytic treatment once the patient has reached hospital. The Australasian Council on Healthcare Standards (ACHS) uses the proportion of patients with acute myocardial infarction who have door to needle times of under 60 minutes as a national clinical indicator. ${ }^{56}$ Other authorities have recommended that the median door to needle time should be under 30 minutes. ${ }^{7}$ Moving the site of decision making and administration of thrombolysis to the emergency department has been recommended to minimise delay in starting the treatment. Previous studies have either compared different thrombolytic strategies between local hospitals or have reviewed trial registry data from hospitals using different pathways. ${ }^{8-12}$ We could locate no studies in a MEDLINE search comparing emergency department with coronary care unit door to needle time in a single institution before and after changing to emergency department initiated thrombolysis.

The departments of cardiology and emergency medicine in our hospital made a joint decision to change to emergency department initiated thrombolysis. This provided an opportunity to assess this intervention prospectively in an Australasian setting. The aim of our study was to document whether a move to emergency department based thrombolysis significantly reduced the door to needle time.

\section{Methods}

The study was conducted at a tertiary teaching hospital in which 35000 patients are seen yearly in the emergency department, with an 


\section{ED time line}

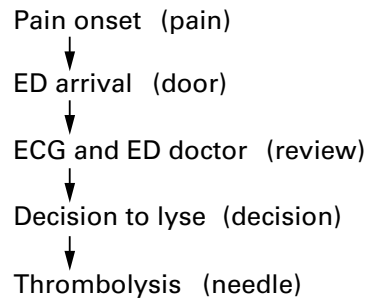

CCU time line

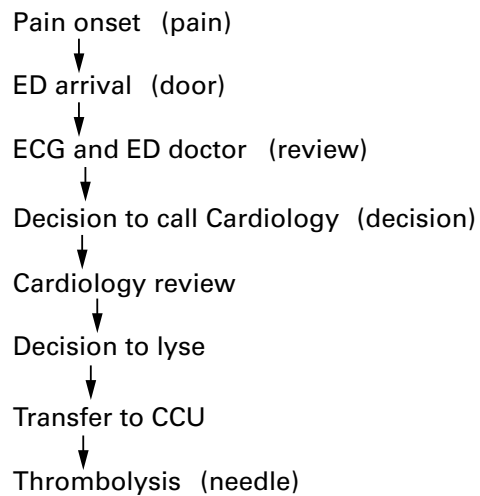

Figure 1 Emergency department (ED) versus coronary care unit timelines for patients receiving thrombolysis. CCU, coronary care unit.

admission rate of approximately $45 \%$. On average 450 to 500 patients a year have a primary diagnosis of acute myocardial infarction by International Classification of Diseases, ninth revision (ICD-9) discharge code.

In early 1994, we developed a fast track protocol for thrombolytic treatment of patients presenting with acute myocardial infarction. Cardiology medical staff assessed eligibility for thrombolysis after early referral from the emergency department, and treatment was given in the coronary care unit after rapid patient transfer. Prospective data collection began several months after this protocol was initiated. In April 1997 an agreement was made between the departments of cardiology and emergency medicine that all patients presenting to the emergency department with acute myocardial infarction and fulfilling criteria for thrombolytic treatment should have the treatment given in the emergency department by emergency physicians.

The study groups consisted of a preintervention group of 89 coronary care unit patients and a postintervention group of 100 emergency department patients. The coronary care unit data were collected prospectively on nonconsecutive patients treated between June 1994 and January 1996. The non-consecutive nature of the data usually reflected administrative problems, but data collection was evenly spread throughout the period of study. A retrospective search was undertaken to identify patients treated in the coronary care unit group who had not been included in the prospective register. Basic demographic, time point, and outcome data were collected to allow comparison against those included in the register. It was logistically impossible to carry out a full review of all 640 patients with acute myocardial infarction admitted during this period, to identify cases where thrombolytic treatment had been missed by the register. The retrospective search used the combination of a code for "streptokinase drug alert" combined with the primary discharge code of acute myocardial infarction, and therefore was likely to miss patients given tissue plasminogen activator (alteplase). An additional search was made using death during the index admission with a primary diagnosis of acute myocardial infarc-

tion, and a subsequent review of case records was performed to review all morbid outcomes associated with thrombolytic treatment in the coronary care unit population.

The emergency department data were collected prospectively on consecutive patients receiving thrombolysis in the department from April 1997 to May 1998. Data from January 1996 to March 1997 were not available owing to technical problems with data collection during that period.

Data were collected in thrombolysis registers located in the respective departments and then transferred to computer spreadsheets. Information collected for both groups included time of pain onset, time of arrival at hospital, time when thrombolytic treatment was started, and intermediate time points that describe the process of care (fig 1). In addition, call to needle times - that is, time from entry to medical system (for example, call to ambulance service) to drug delivery) - were calculated from the St John Ambulance database if patients were in the database.

Demographic data, site of infarct, type of thrombolytic agent, and outcome data (including deaths, inappropriate thrombolysis, and complications of treatment) were collected. These were gathered by reviewing the medical record at a later date. Delays associated with initially non-diagnostic ECGs or entry into clinical trials did not lead to exclusion from the study. Pharmacy records were reviewed to establish the overall use of thrombolytic agents for patients with myocardial infarcts during the study periods. The numbers of patients with a primary diagnosis of acute myocardial infarction for each year were calculated from the ICD-9 discharge codes.

As a registered quality improvement activity, the study was exempt from requiring ethics committee approval.

\section{STATISTICAL ANALYSIS}

Univariate analysis was performed on continuous and categorical variables. Medians were calculated for all time intervals, and the Mann-Whitney test used to determine differences in these intervals between emergency department and coronary care unit; $95 \%$ confidence intervals (CI) were calculated around differences between the two clinical units in the proportion of patients receiving thrombolysis within specific time intervals. Fisher's exact test (two tailed) was used to compare discrete contingency table variables. Analysis was undertaken using the Statistical Package for Social Sciences (SPSS; version 8.0) and significance was achieved at $\alpha<0.05$.

Table 1 Site of acute myocardial infarction (AMI)

\begin{tabular}{lll}
\hline Site of infarct & $\begin{array}{l}\text { Emergency department } \\
\text { group (\%) }\end{array}$ & $\begin{array}{l}\text { Coronary care unit } \\
\text { group (\%) }\end{array}$ \\
\hline Anterior & $40(40)$ & $40(45)$ \\
Inferior & $57(57)$ & $47(53)$ \\
Posterior & $1(1)$ & $1(1)$ \\
No AMI & $2(2)$ & $1(1)$
\end{tabular}

No significant differences between the groups. 
Table 2 Comparison of characteristics of coronary care unit (CCU) patients collected prospectively with those in a retrospective population survey

\begin{tabular}{lll}
\hline & $\begin{array}{l}\text { Prospective } \\
\text { CCU patients }\end{array}$ & $\begin{array}{l}\text { Retrospective } \\
\text { CCU patients }\end{array}$ \\
\hline Numbers & 89 & 69 \\
Age (streptokinase only); M:F ratio & $63(62.5) ; 63: 26$ & $65(65) ; 47: 22$ \\
$\star$ Agent-streptokinase:alteplase & $66: 23$ & $62: 7$ \\
$\star$ AMI site-inferior:anterior:other & $47: 39: 3$ & $42: 22: 5$ \\
†Median pain to needle time (mean) & $195(227)$ & $237(281)$ \\
†Median door to needle time (mean) & $80(88)$ & $81(98)$ \\
Deaths/intracranial haemorrhage & $3 / 0$ & $13 / 0$ \\
Median pain to door time (mean) & $108(138)$ & $138(172)$ \\
\hline
\end{tabular}

${ }^{\star}$ Retrospective data are weighted to streptokinase patients, missing most episodes of alteplase use. This excludes a predominantly younger group (less than 70 years) and anterior infarcts (standard eligibility criteria for alteplase at the time), with possibly earlier presentations.

†Data calculated on sample of 56 patients only (initial group found by drug alert (streptokinase) + diagnosis of acute myocardial infarction).

AMI, acute myocardial infarction.
The age and sex distribution, times to thrombolysis, and outcomes for the register and non-register (retrospective) populations for the coronary care unit group are compared in table 2. The apparently lower rate of alteplase use in the non-register coronary care unit patients and the higher mean and median age in part reflect the inability to identify retrospectively those patients receiving alteplase who were not included in the register. There was no significant difference in median door to needle time between the prospective and retrospective coronary care unit patients, even though other variables were different-for example, more late presentations and an older population (streptokinase patients).

No differences were observed between the groups in the time taken for patients to reach hospital following the onset of pain (table 3). The difference in the median time taken to decide whether to give thrombolytic drugs in the emergency department group compared with the time taken by emergency department physicians to call a cardiologist in the coronary care unit group was not significant (29 $v 30$ minutes; $\mathrm{p}=0.705)$.

Median door to needle time for emergency department patients was 37 minutes (95\% CI 33 to 44 ) compared with 80 minutes $(95 \%$ CI 70 to 89 ) for coronary care unit patients $(p<0.0001)$. Only one of the coronary care unit patients $(1 \%)$ had a door to needle time of 30 minutes or less, compared with 32 emergency department patients (32\%; difference $31 \%, 95 \%$ CI $22 \%$ to $40 \%$, p < 0.0001 ) (fig 2 ). For emergency department patients, 83 (83\%) met the performance indicator of a door to needle time of 60 minutes or less versus 23 $(26 \%)$ coronary care unit patients (difference $57 \%, 95 \%$ CI $45 \%$ to $69 \%, \mathrm{p}<0.0001$ ) (fig 2 )

Pain to thrombolysis time was significantly shorter in the emergency department patients (table 3). In the emergency department group, 18 patients $(18 \%)$ received thrombolysis within 90 minutes of pain onset, versus one patient in the coronary care unit group (1\%) (difference $17 \%, 95 \%$ CI $9 \%$ to $25 \%, p=0.0001)$.

There was no significant difference in overall in-hospital mortality between patients treated in the emergency department and the total number treated in the coronary care unit during the study period $(12 / 100(12 \%)$ and $16 / 180$ $(9 \%)$, respectively; $\mathrm{p}=0.5343,95 \%$ CI $5.5 \%$ to $27 \%$ ). However, the case fatality rate was $8 / 100$ in the emergency department group $(\mathrm{p}>0.05)$.

Table 3 Comparison of pain to door, door to decision, door to needle, and pain to needle times

\begin{tabular}{|c|c|c|c|c|c|}
\hline & \multicolumn{5}{|c|}{ Time periods (minutes) } \\
\hline & Pain to door & Door to decision & Pain to needle & Call to needle & Door to needle \\
\hline Emergency department & & & & $\mathrm{n}=56 / 89$ & \\
\hline Mean & 145 & 37 & 193 & 110 & 47 \\
\hline Median $(95 \% \mathrm{CI})$ & $110(92$ to 125$)$ & 29 (25 to 33$)$ & 161 (142 to 177$)$ & 84 & 37 (33 to 44$)$ \\
\hline Range & 0 to 748 & 6 to 251 & 56 to 856 & 35 to 990 & 10 to 256 \\
\hline Coronary care & & & & $\mathrm{n}=69 / 100$ & \\
\hline Mean & 138 & 37 & 227 & 141 & 88 \\
\hline Median $(95 \% \mathrm{CI})$ & $108(83$ to 121$)$ & 30 (23 to 38$)$ & 195 (180 to 209$)$ & 123 & $80(70$ to 89$)$ \\
\hline Range & 22 to 755 & 5 to 268 & 70 to 880 & 66 to 858 & 20 to 330 \\
\hline Mann-Whitney* & 4301.5 & 4308.0 & 3377.5 & 826.0 & 1449.0 \\
\hline $\mathrm{p}$ Value & 0.692 & 0.705 & 0.004 & $<0.0001$ & $<0.0001$ \\
\hline
\end{tabular}

^Mann-Whitney U test significance score for non-normally distributed populations. 


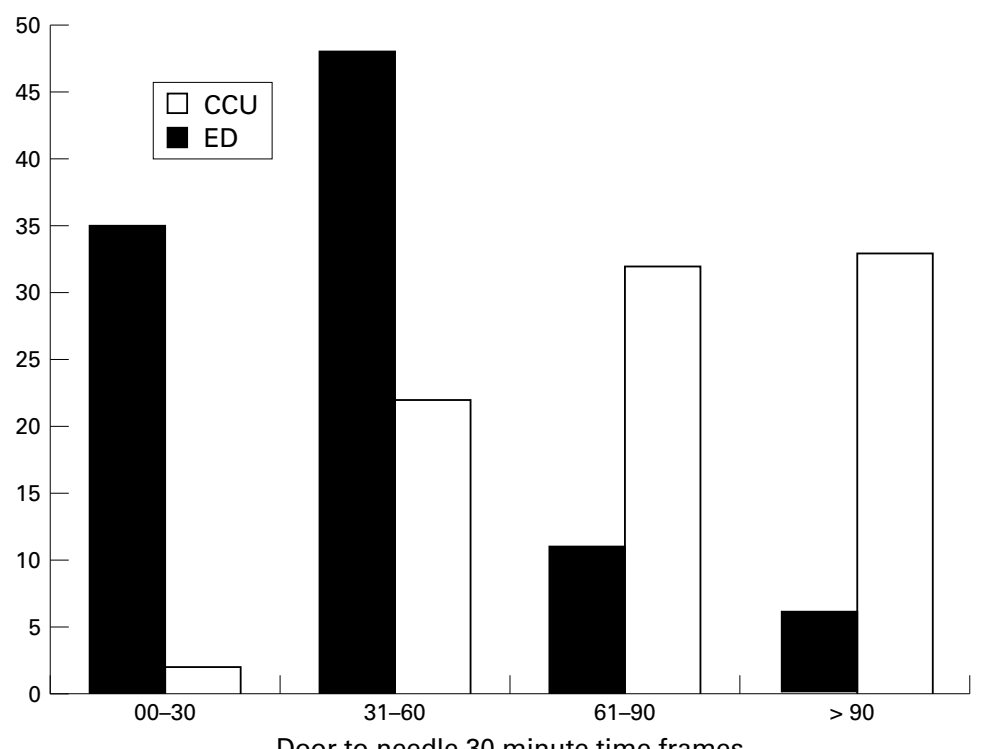

Door to needle 30 minute time frames

Figure 2 Comparison of numbers of patients from the emergency department (ED) versus the coronary care unit (CCU), with door to needle times in four 30 minute frames.

higher in the emergency department patients when they were compared with the prospective coronary care unit group $(12 / 100(12 \%) v 3 / 89$ (3.4\%); difference $8.4 \%, 95 \%$ CI $2 \%$ to $16 \%$, $\mathrm{p}=0.021)$.

Intracranial haemorrhage was confirmed in one emergency department patient and suspected in another, but the clinical course was inconclusive and a necropsy examination was not done. One emergency department patient with aortic dissection secondary to EhlersDanlos syndrome received thrombolysis and subsequently died. Significant non-fatal complications of thrombolysis in the emergency department group included three gastrointestinal bleeds and one allergic reaction to streptokinase. In the coronary care unit group there were five gastrointestinal bleeds, one haemoptysis, and one allergic reaction to streptokinase. Inappropriate thrombolysis, defined as a discharge diagnosis other than acute myocardial infarction, occurred in one of the 89 coronary care unit patients and three of the 100 emergency department patients ( $p>0.05)$.

\section{Discussion}

Door to needle time is a marker of system efficiency, and a reduced door to needle time should lead to a reduced pain to needle time. ${ }^{9-11}$ Better patient outcomes, with reductions in the time from symptom onset to the administration of thrombolysis, have been shown by analysing subgroups from large thrombolytic trials. ${ }^{1-4}$ The GREAT (Grampian Region early anistreplase trial) study and Cocchinelli's study are unique in that they effectively randomised two groups to differing pain to thrombolysis times. ${ }^{13-16}$ This was done by giving thrombolytic agents to one group at home or in a rural emergency department, and comparing those patients with a second group receiving thrombolytic treatment in an urban coronary care unit. These studies show that reduced pain to needle time significantly improved short and long term outcomes.

In our study, moving thrombolysis to the emergency department was associated with a major reduction in the median door to needle time (from 80 to 37 minutes), with a notable improvement in the numbers of patients treated within the ACHS guideline of $60 \mathrm{~min}-$ utes $(83 \% v 26 \%) .{ }^{6}$ This number is more impressive when it is considered that there were no exclusions in our study, even though the ACHS guidelines suggest including only patients with ST elevation on arrival at the hospital. ${ }^{6}$ Moreover the reduction in door to needle time translates into a similar reduction in pain to needle time, with a notable increase in early thrombolysis (under 90 minutes, 18\% $v 1 \%$ ). There is evidence that very early thrombolysis provides greater benefit in patients with acute myocardial infarction. ${ }^{15-17}$

There was a median 30 minute delay before the cardiologist was called, similar to the 29 minute delay for emergency physicians to decide on thrombolysis. The coronary care unit group in this study encountered additional delay at two specific phases (fig 1). The first was the time interval between the cardiologist being called and the final decision to give thrombolysis; the second was the delay associ-

Table 4 Clinical details of deaths in prospectively studied emergency department and coronary care unit patients

\begin{tabular}{|c|c|c|c|c|}
\hline $\begin{array}{l}\text { Age/sex/infarct site/ST changes/ } \\
\text { prelysis CCU review }\end{array}$ & $t P A / S K$ & Time to death & Cause of death & Initial hypotension/CCF \\
\hline \multicolumn{5}{|l|}{ Coronary care unit deaths (3) } \\
\hline $81 / \mathrm{F} / \mathrm{inf} / 3 \times 1 \mathrm{~mm} /$ yes & SK & 10 days & Cardiogenic failure & No, but recurrent episodes during admission \\
\hline 81/F/new LBBB/yes & SK & 8 days & Arrest after $8 / 7$ low output failure & Initial shock, SBP 70; severe LV dysfunction \\
\hline $72 / \mathrm{F} / \mathrm{ant} / 4 \times 4 \mathrm{~mm} / \mathrm{yes}$ & tPA & 3 days & $\begin{array}{l}\text { Pulseless electrical activity; probable } \\
\text { tamponade }\end{array}$ & No \\
\hline \multicolumn{5}{|l|}{ Emergency department deaths (12) } \\
\hline $46 / \mathrm{M} / \mathrm{ant} / 4 \times 4 \mathrm{~mm} / \mathrm{yes}$ & $\mathrm{tPA}$ & 4 days & Cardiogenic shock; died post-CABG & SBP 70; persistent hypotension \\
\hline $88 / \mathrm{M} / \mathrm{ant} / 3 \times 6 \mathrm{~mm} / \mathrm{yes}$ & SK & 4 days & Arrest after day 4 ; cardiac failure & SBP 90; inotrope dependent before arrest \\
\hline $54 / \mathrm{M} /$ ant lat inf $/ 8 \times 2 \mathrm{~mm} / \mathrm{no}$ & SK & 4 hours & Aortic dissection; tamponade & Ehlers-Danlos syndrome \\
\hline $74 / \mathrm{F} / \mathrm{inf}$ lat $/ 6 \times 1 \mathrm{~mm} / \mathrm{no}$ & SK & 1 hour & Sudden hypotensive arrest & Yes; occurred rapidly after thrombolysis \\
\hline $77 / \mathrm{F} / \mathrm{ant} / 4 \times 7 \mathrm{~mm} / \mathrm{no}$ & SK & 3 davs & New VSD day $2 ;$ VF arrest & Mild pulmonary oedema; hypotensive after VSD \\
\hline $87 / \mathrm{M} / \mathrm{inf}$ post $/ 6 \times 2 \mathrm{~mm} / \mathrm{no}$ & SK & 6 days & New ST changes day 6 ; hypotensive demise & 2nd AMI; not for thrombolysis/resuscitation \\
\hline $77 / \mathrm{F} / \mathrm{inf} / 2 \times 4 \mathrm{~mm} / \mathrm{yes}$ & SK & 12 days & Cardiogenic shock & Inotrope dependent before arrest \\
\hline $83 / \mathrm{F} / \mathrm{ant} / 4 \times 5 \mathrm{~mm} / \mathrm{yes}$ & SK & 5 days & Intracranial haemorrhage & $\begin{array}{l}\text { SBP } 180 \text { at time of thrombolysis; decision made } \\
\text { by cardiologist }\end{array}$ \\
\hline $84 / \mathrm{M} / \mathrm{ant} / 4 \times 5 \mathrm{~mm} / \mathrm{no}$ & SK & 9 days & VSD; arrest after & Not hypotensive on arrival; VSD late \\
\hline $78 / \mathrm{F} / \mathrm{inf} / 3 \times 6 \mathrm{~mm} / \mathrm{no}$ & SK & 3 days & Cardiogenic shock & Gradual decrease in SBP \\
\hline $89 / \mathrm{M} / \mathrm{ant} / 3 \times 4 \mathrm{~mm} / \mathrm{no}$ & SK & 4 days & VF arrest; not for resuscitation & Initial SBP 80; severe LV dysfunction \\
\hline $67 / \mathrm{M} / \mathrm{inf}$ post $/ 5 \times 4 \mathrm{~mm} / \mathrm{no}$ & $\mathrm{SK}(0.8 \mathrm{MU})$ & 4 hours & Rescue angioplasty; hypotensive arrest & BP fell during SK; persisted after angioplasty \\
\hline
\end{tabular}

Ant, anterior; BP, blood pressure; CABG, coronary artery bypass graft; CCF, congestive heart failure; inf, inferior; LBBB, left bundle branch block; LV, left ventricular; post, posterior; SBP, systolic blood pressure; SK, streptokinase; tPA, alteplase; VF, ventricular fibrillation; VSD, ventricular septal defect. 
ated with transferring the patient from the emergency department to the coronary care unit.

These findings suggest that the reduction in door to needle time resulted from a system change and not from faster decision making by the emergency physicians. During the period when thrombolysis shifted from coronary care unit to emergency department there was a significant increase in emergency department doctor staffing numbers and seniority. There is no doubt that an improvement in staffing and seniority of staff in the emergency department could lead to quicker decisions to involve the coronary care unit. However, the decision time in the emergency department was still $30 \mathrm{~min}-$ utes after the change to emergency department thrombolysis, suggesting that changes in staffing in the department were not the major reason for reduced times. While reduction in door to needle time to 37 minutes is a major improvement, it is probable that this could be reduced further with additional strategies. ${ }^{18} 19$

Because the coronary care unit data were non-consecutive, we retrospectively reviewed the non-registered thrombolysis population to check for potential systematic bias. In these cases the patients were slightly older and had more inferior acute infarcts and longer times to arrival. This probably reflects the fact that these patients were mainly streptokinase recipients, as these tend to be older and have more inferior infarcts. Older patients are also known to present later to hospital. Decisions about thrombolysis in these patients may be more time consuming, given associated factors such as their late presentations and the presence of significant age related comorbidity or relative contraindications. However, we found that their door to needle times were virtually the same as the prospective group and hence systematic bias is unlikely.

We have looked at safety issues for changing the site of delivery. Because of the size of the study it is not possible to prove whether the change is without consequences for safety. There was no overall difference in in-hospital mortality in patients treated in the emergency department compared with the coronary care unit. In the prospective study groups, however, there was an apparent increase in deaths in emergency department treated patients $(12 \%$, $v 3.4 \%$ in the coronary care unit; $\mathrm{p}=0.021$ ). Several factors may have contributed to this finding.

First, the overall mortality in the coronary care unit group is calculated to be $9 \%$ (table 3; non-significant difference between emergency department and coronary care unit). This may be an underestimate as in the last 22 patients without data some may have been excluded if they had in-hospital infarcts, infarcted late during coronary care unit admission, or infarcted after angioplasty.

Second, both rates are within the range of reported mortality. ${ }^{122021}$ However, the rate in the prospective coronary care unit series is similar to low risk groups from trials, while the emergency department rate is similar to current registry data. ${ }^{22}$
Third, in the earlier period thrombolysis may have been more conservative. This has been clearly shown in longitudinal studies when new treatments are instituted. ${ }^{23}$ There was more use of alteplase in the emergency department population. We also reviewed age groups in the two populations and only three of the 89 patients were older than 80 years (two deaths) in the coronary care unit group, versus 11 of 100 in the emergency department population (five deaths). Older patients are known to have a much higher mortality (with or without thrombolysis). ${ }^{24}$

Fourth, a type I error is possible. The subsequent 100 patients thrombolysed in the emergency department had an in-hospital mortality of $6 \%$.

Fifth, a learning curve for emergency department thrombolysis may be present. Two deaths in the emergency department group were considered errors of judgement (table 4). However, the other 10 cases were considered appropriate.

Sixth, owing to a longer delay to thrombolysis in the coronary care unit group, several patients with early cardiogenic shock or hypotension may have succumbed or become too sick before they could receive thrombolysis. In the emergency department deaths, early signs of cardiogenic shock were seen in five patients within the first few hours.

There was one definite and one possible intracranial bleed in the emergency department group. This is well within the expected rate of intracranial bleeds from other studies. ${ }^{1-3}$ The proportion of patients misdiagnosed in the emergency department group was 3\%, again well within reported rates. ${ }^{12} 2526$

Reducing door to needle time has been a significant problem for many centres. Strategies other than moving thrombolysis from the coronary care unit to the emergency department have been examined. These have included instituting ECGs and thrombolysis in the prehospital setting, ${ }^{13}{ }^{16}$ fast tracking patients directly to the coronary care unit from general practitioners and ambulances, ${ }^{27}{ }^{28}$ and hospitals improving their systems approaches and increasing staff education. ${ }^{29}{ }^{30}$ In an urban setting such as ours with short transport times, prehospital thrombolysis is unlikely to achieve significant time reductions relative to resource requirements. ${ }^{31}$ Fast tracking patients falls short in failing to recruit all appropriate patients and leads to patients with non-cardiac diagnoses using coronary care unit beds. ${ }^{25}$ Also the gains achieved tend to drop off rapidly. The experience in this hospital was that fast tracking reduced times from 80 to 65 minutes but the reduction was unsustainable. Staff education and hospital promotion of thrombolysis tend to lead to short term gains that are easily lost. ${ }^{30}$ In the present urban teaching hospital setting, moving thrombolysis delivery to the emergency department was a highly effective way of achieving significant and sustainable reductions in door to needle time. 
LIMITATIONS

We recognise various potential limitations of this study. First, the study was observational and relied on historical controls, with the possibility that the two populations were very different. However, we feel this is unlikely as the data were collected prospectively and demographic data, pain to door time, and infarct location were similar between the two populations. This suggests that the populations were well matched and were treated similarly. Indeed if there was any bias it would seem to be to the benefit the coronary care unit group, as deaths and patients with later arrival times were found in the non-register population. The hospital had no major change in its catchment population during the time of the study. There was a small change in the numbers of patients coded with a primary ICD-9 discharge code for acute myocardial infarction (1994, 593; 1995, $520 ; 1997,483 ; 1998,468)$ and almost no change in the numbers of patients attending the emergency department $(35000 \pm 1000)$; neither have there been any major changes in treatment of acute myocardial infarction offered at this hospital over the study period. Although the percentage of patients given thrombolytic agents acutely was low (about $20 \%$ of all patients with a discharge code of acute myocardial infarction), it was similar for the two groups. The only notable difference was an increase in older age groups receiving thrombolysis in the emergency department population and greater use of alteplase. Each could be expected to increase door to needle times.

When the new system was introduced the data collected for the emergency department patients were comprehensive and consecutive to ensure that the quality of the new service was adequate, particularly with regard to safety.

The possibility of ongoing trials leading to delays has been documented in other papers. $^{32} 33$ Patients were recruited to trials during both study periods and in similar numbers, and therefore this was unlikely to bias the results. Moving thrombolysis to the emergency department did not stop recruitment for trials. A possible criticism is that we have not shown a beneficial clinical outcome, but given the numbers of patients available this was never a possibility and was not an aim of the study.

Finally we did not manage to include all patients with thrombolysis in the retrospective coronary care unit review owing to logistical problems. However, most were alteplase patients and the numbers were small. These patients were likely to have larger and more complex infarcts, and in the prospective group had longer door to needle times. It is therefore unlikely that their inclusion would decrease the observed door to needle time and would probably have increased it.

\section{CONCLUSIONS}

This prospective observational study has shown that, with a collaborative approach between the emergency department and coronary care unit, delivery of thrombolysis for acute myocardial infarction in the emergency department leads to very important time benefits. The benefit was achieved in a safe manner with diagnostic accuracy and adverse outcomes well within those already reported. We feel that this study, along with trials from other countries, shows that moving thrombolysis to the emergency department is an easy and effective way of reducing and sustaining reductions in door to needle time. This translates to reduced pain to needle times, with likely benefits in terms of mortality and morbidity. In particular, we have demonstrated this in a contemporary Australasian setting.

We are grateful to all those who have constructively reviewed and commented on this paper. Their valuable contributions have led to a better paper and we feel the extra effort involved has been worthwhile and productive.

1 GISSI Investigators. Effectiveness of intravenous thromboytic treatment in acute myocardial infarction. Lancet 1986;i:397-402

2 ISIS-2 Collaborative Group. Randomized trial of intravenous streptokinase, oral aspirin, both, or neither among 17187 cases of suspected acute myocardial infarction: ISIS-2. Lancet 1988;ii:349-60.

3 GUSTO investigators. An international randomized trial comparing four thrombolytic strategies for acute myocardial infarction. N Engl f Med 1993;329:673-82.

4 Fibrinolytic Therapy Trialists' (FTT) Collaborative Group. Indications for fibrinolytic therapy in suspected acute myocardial infarction: collaborative overview of early mortality and major morbidity results from all randomized trials or more than 1000 patients. Lancet 1994;343:311-22.

5 Ralk E. Thrombolytic therapy for myocardial infarction: standards versus clinical indicators [letter]. Med f Aust standards versur.

6 Australasian Council for Healthcare Standards. Clinical indicators-a users' manual, version 2:17. Sydney, 1998.

7 National Heart Attack Alert Program Coordinating Committee, 60 Minutes to Treatment Working Group. Emergency department: rapid identification and treatment of patients with acute myocardial infarction. Ann Emerg Med 1994;23:311-29.

8 Sharkey SW, Brunette DG, Ruiz E, et al. An analysis of time delays preceding thrombolysis for acute myocardial infarction. FAMA 1989;262:3171-4.

9 Birkhead JS. Time delays in provision of thrombolytic treatment in six district hospitals. BMF 1992;305:445-8.

10 Gonzalez ER, Jones LA, Ornato JP, et al. Hospital delays and problems with thrombolytic administration in-patients receiving thrombolytic therapy: a multicentre prospective assessment. Ann Emerg Med 1992;21:1215-21.

11 Lambrew CT, Bowlby LJ, Rogers WJ, et al. Factors influencing the time to thrombolysis in acute myocardial influencing the time to thrombolysis in acute
infarction. Arch Intern Med 1997;157:2577-82

12 Kendall JM, McCabe SE. The use of audit to set up a thrombolysis programme in the accident and emergency thrombolysis programme in the accident and

13 GREAT Group. Feasibility, safety, and efficacy of domiciliary thrombolysis by general practitioners: Grampian region early anistreplase trial. $B M \mathcal{F}$ 1992;305:548-53.

14 Rawles J. Magnitude of benefit from earlier thrombolytic treatment in acute myocardial infarction: new evidence from Grampian region early anistreplase trial (GREAT). $B M \mathcal{1}$ 1996;312:2212-15

15 Rawles J. Quantification of the benefit of earlier thrombolytic therapy: five year results of the Grampian Region early anistreplase trial (GREAT). F Am Coll Cardiol 1997;30: 1181-6.

16 Coccolini S, Berti G, Bosi S, et al. Prehospital thrombolysis in rural emergency room and subsequent transport to a coronary care unit: Ravenna Myocardial Infarction (RaMI) coronary care unit: Ravenna Myocardi

17 Boersma E, Maas AC, Deckers JW, et al. Early thrombolytic treatment in acute myocardial infarction: reappraisal of the treatment in acute myocardial infarction.
golden hour. Lancet 1996;348:771-5.

18 Steele MT, Hansen JW, Watson W. Thrombolytic therapy in Missouri hospital emergency departments: compliance with the National Heart Attack Alert Program guidelines. Mo Med 1998;95:179-83.

19 Berglin Blohm M, Nilsson G, Karlsson T, et al. The possibility of influencing components of hospital delay time within emergency departments among patients with ST-elevation in the initial electrocardiogram. Eur F Emerg Med 1998;5:289-96.

20 ISIS-3 (Third International Study of Infarct Survival) Collaborative Group. ISIS-3: a randomised comparison of streptokinase vs tissue plasminogen activator vs anistreplase and of aspirin plus heparin $v s$ aspirin alone amistreplase and of aspirin plus heparin vs aspirin alone among 41,299 cases of suspected

21 Gruppo Italiano per lo Studio della Sopravvivenza nell'Infarto Miocardico. GISSI-2: a factorial randomised trial of alteplase versus streptokinase and heparin versus no trial of alteplase versus streptokinase and heparin versus no
heparin among 12,490 patients with acute myocardial infarction. Lancet 1990;336:65-71. 
22 French JK, Williams BF, Hart $\mathrm{HH}$, et al. Prospective evaluation of eligibility for thrombolytic therapy in acute

23 Maynard C, Martin JS, Hallstrom AP, et al. Changes in the use of thrombolytic therapy in Seattle Area hospitals from 1988 to 1992: results from the Myocardial Infarction Triage and Intervention Registry. F Thromb Thrombolysis 1995;1:195-9.

24 Gottlieb S, Goldbourt U, Boyko V, et al. Improved outcome of elderly patients ( $\geqslant 75$ years of age) with acute myocardial infarction from 1981-1983 to 1992-1994 in Israel. The SPRINT and thrombolytic survey groups. Secondary prevention reinfarction Israel nifedipine trial. Circulation 1997;95:342-50.

25 Althouse R, Maynard C, Cerqueira MD, et al. The Western Washington myocardial infarction registry and emergency department tissue plasminogen activator treatment trial. Am f Cardiol 1990;66:1298-303.

26 Pell AC, Miller HC, Robertson CE, et al. Effect of "fast track" admission for acute myocardial infarction on delay to thrombolysis. BMF 1992;304:83-7.
27 Prasad N, Wright A, Hogg KJ, et al. Direct admission to the coronary care unit by the ambulance service for patients with myocardial infarction. Heart 1997;78:462-4.

28 Thomas D, Cooper L, Cooper J, et al. Direct fast track admission to a coronary care unit. $\mathcal{F} R$ Coll Physicians Lond 1997;31:188-91.

29 Porter G, Doughty R, Gamble G, et al. Thrombolysis in acute myocardial infarction: reducing inhospital treatment delay. NZ Med f 1995;108:253-4.

30 Wilkes GJ, Mountain D. Improving emergency department time to thrombolysis [abstract]. Emerg Med 1997;9:67.

31 Myers RB: Prehospital management of acute myocardial infarction: electrocardiogram acquisition and interpretation, and thrombolysis by prehospital care providers. Can J Cardiol 1998;14:1231-40.

32 Dunn R. Trial participation leads to a delay in thrombolysis for acute myocardial infarction [letter]. Emerg Med 1998;10:77.

33 Aitken P, Green D. Trial participation leads to a delay in thrombolysis for acute myocardial infarction. Emerg Med 1997;9:311-16.

\section{Electronic pages}

\section{eHEART: www.heartinl.com}

The following electronic only articles are published in conjunction with this issue of Heart.

\section{Secondary prevention of hypercholesterolaemia: results of an audit conducted in South Wales \\ L S Cozma, A Ogunko, A Ress}

Objective-To audit the standards of secondary prevention of coronary heart disease in postmyocardial infarction patients. Design-Follow up audit, one year after acute admission with myocardial infarction.

Setting-University Hospital.

Subjects-For the initial admission, 153 patients were audited, with 84 patients contacted one year later. Demographic data, treatment status, and cholesterol levels were analysed both on admission and at follow up.

Interventions - Total cholesterol was checked at the audit time either in the hospital or in the doctor's surgery.

Main outcome measures - Statin doses and cholesterol levels. Results-Ninety six per cent of patients had their lipid profile performed on admission. Eighty three per cent of the patients with total cholesterol $\geqslant 5 \mathrm{mmol} / \mathrm{l}$ were discharged from the hospital on lipid lowering medication. Forty five per cent of the subjects who were followed up had cholesterol levels $\geqslant 5 \mathrm{mmol} / \mathrm{l}$ at 1 year. There was a disproportionate use of low doses of statins (lower than those shown in effective trials: simvastatin 20 to $40 \mathrm{mg}$, pravastatin $40 \mathrm{mg}$ ) with a third of all patients on medication not achieving the targets at one year.

Conclusion-There was a major improvement in the proportion of patients started on treatment compared with figures reported by previous studies. However, the titration of the statin doses to achieve the targets is still unsatisfactory. (Heart 2000;84:e3) www.heartjnl.com/cgi/content/full/84/ $2 / \mathrm{e} 3$

Sildenafil as a selective pulmonary vasodilator in childhood primary pulmonary hypertension D Abrams, I Schulze-Neick, A G Magee

Primary pulmonary hypertension is a rare disease of childhood, which carries a poor prognosis. Patients often present with severe exercise limitation, and untreated life expectancy is less than 1 year. Pharmacological intervention is directed towards reduction of the raised pulmonary artery pressure with vasodilator treatment, initially with calcium antagonists, although more recently long term prostacyclin treatment has shown benefit in some patients. Heart-lung transplantation remains an option for children with severe disease refractory to therapeutic treatment. A 4 year old Bangladeshi girl with dyspnoea, cyanosis, and signs of a low cardiac output, is described. Initial treatment with prostacyclin was gradually reduced, and maintenance treatment with oral sildenafil (Viagra; Pfizer) instituted. At follow up 3 months later, her exercise capacity was greatly improved and she continues to enjoy a good quality of life without obvious side effects. In view of the encouraging initial results, this may become an acceptable adjunct in treating this patient group.

(Heart 2000;84:e4) www.heartinl.com/cgi/content/full/84/ $2 / \mathrm{e} 4$

\section{Life threatening coronary artery spasm in} childhood Kimura's disease

H Horigome, T Sekijima, S Ohtsuka, M Shibasaki

A 13 year old boy is described with hypereosinophilia associated with Kimura's disease, who showed repeated life threatening syncopal attacks during daily activities or at rest. Coronary arteriography demonstrated small aneurysms with irregular vessel walls of both coronary arteries, and the absence of organic stenotic lesions. Infusion of a minimal dose of ergonovine into the right coronary artery induced severe spasm of the vessel. Ventricular fibrillation recurred even after administration of nifedipine and isosorbide was started, but was completely inhibited by prednisolone.

(Heart 2000;84:e5) www.heartjnl.com/cgi/content/full/84/ $2 / \mathrm{e} 5$ 